\title{
Protection pour votre famille
}

Une grave maladie ou un accident touche gravement une famille en cas d'incapacité de travail du principal apporteur de revenu et a des suites financielles très importantes. Connaissez-vous quelles seraient les prestations à disposition de votre famille? Lors de votre analyse de prévoyance personnelle, nous vous indiquons quelles prestations vous sont dues en cas de décès, d'incapacité de gain ou lors de la retraite. Ainsi nous découvrons les cas de sous- et/ou sur-assurance et pouvons prendre les mesures nécessaires afin de protéger votre famille.

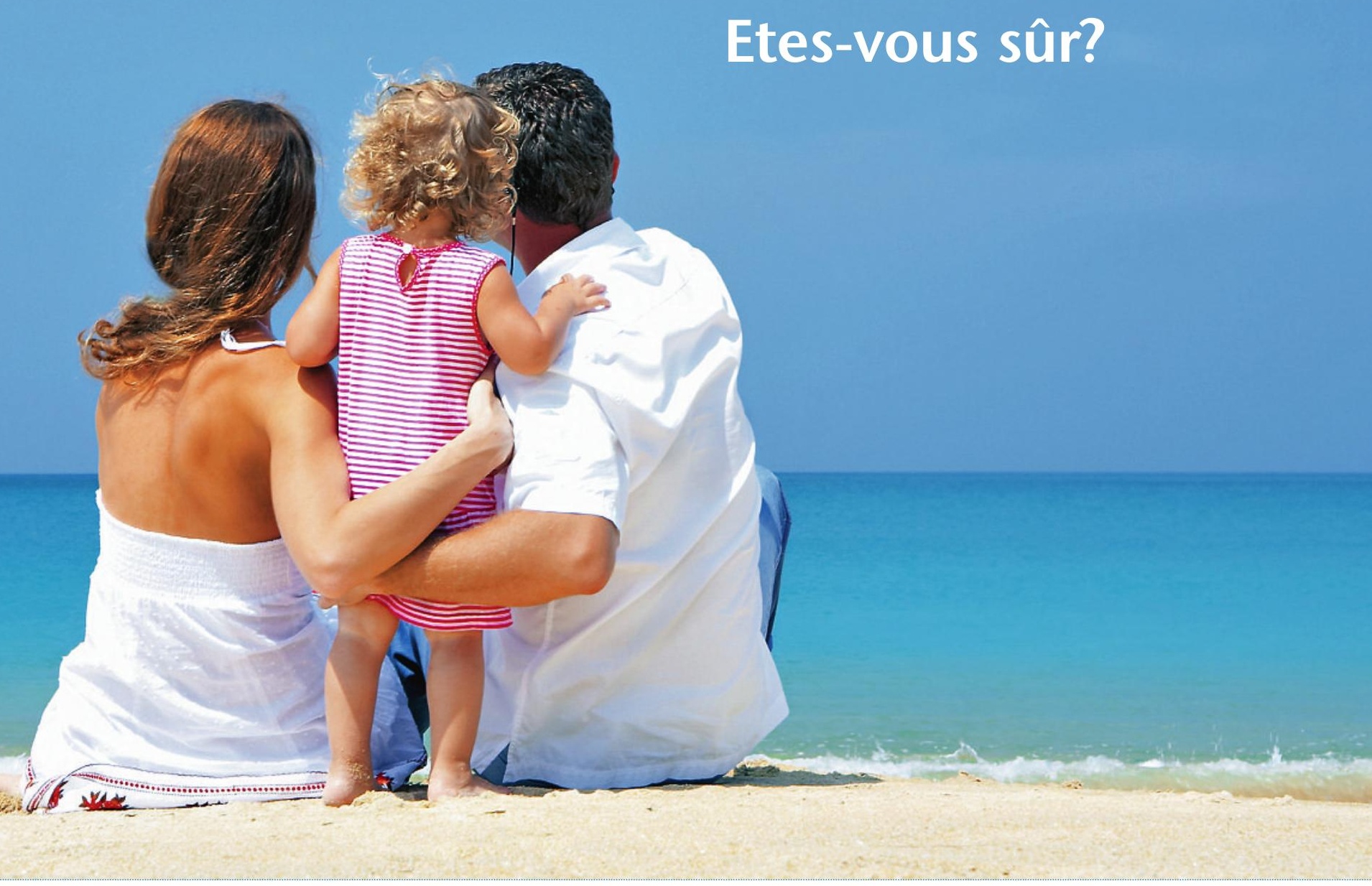

$\square$ Je veux contrôler les prestations pour moi et ma famille et désire me laisser conseiller. Prière de me téléphoner.

\section{Prénom / Nom}

Adresse

NPA / Lieu

Date de naissance

Téléphone privé / cabinet

Atteignable le plus facilement

Adresse E-Mail

\section{Etes-vous sûr?}

\section{G'FMH INSURANCE}

Roth Gygax \& Partner AG - Service de coordination Moosstrasse 2 a 3073 Gümligen

Téléphone 0319595000 * Fax 0319595010 mail@fmhinsurance.ch n www.fmhinsurance.ch 